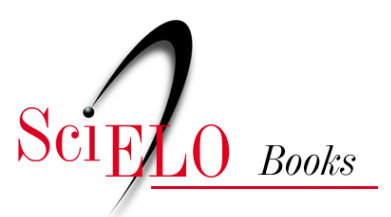

\title{
6 Tribo Stifftieae D. Don
}

\author{
Lúcia Moura Conti \\ Nádia Roque
}

CONTI, L.M., and ROQUE, N. Tribo Stifftieae D. Don. In: ROQUE, N. TELES, A.M., and NAKAJIMA, J.N., comp. A família Asteraceae no Brasil: classificação e diversidade [online]. Salvador: EDUFBA, 2017, pp. 61-65. ISBN: 978-85-232-1999-4. https://doi.org/10.7476/9788523219994.0008.

All the contents of this work, except where otherwise noted, is licensed under a Creative Commons Attribution 4.0 International license.

Todo o conteúdo deste trabalho, exceto quando houver ressalva, é publicado sob a licença Creative Commons Atribição $\underline{4.0}$.

Todo el contenido de esta obra, excepto donde se indique lo contrario, está bajo licencia de la licencia Creative Commons Reconocimento 4.0. 


\title{
TRIBO STIFFTIEAE D. DON
}

\author{
हो \\ Lúcia Moura Conti \\ Nádia Roque
}

A tribo Stifftieae foi descrita por Don (1830) para incluir espécies de Stifftia J.C. Mikan, Anastraphia D. Don e Pentaphorus D. Don. Para o autor, a tribo poderia ser reconhecida pelas flores bissexuais, corola tubulosa, receptáculo epaleáceo, estames insertos na corola, anteras sagitadas e estigma papiloso. Posteriormente, diversos autores (CABRERA, 1977; MAGUIRE et al., 1957, PRUSKI, 1991) consideraram as espécies com corola actinomorfa de Stifftia e outros gêneros centrados nos tepuis (Guianas e Venezuela), como representantes da tribo Mutisieae. Em seguida, Pruski (2004) e Jeffrey (2004), acompanhados por Katinas e colaboradores (2008), recircunscreveram a tribo Stifftieae para incluir 6 gêneros (Chimantaea Maguire, Steyerm. \& Wurdack, Quelchia N.E. Br., Stenopadus S.F. Blake Stifftia, Stomatochaeta Maguire \& Wurdack e Wunderlichia Riedel ex Benth.) e 48 espécies, com base nos capítulos discoides e ramos do estilete rugosos a papilosos dorsalmente.

Estudos com base em marcadores moleculares (FUNK et al., 2009; PANERO; FUNK, 2008) propuseram uma nova circunscrição para a tribo Stifftieae, incluindo 11 gêneros, agrupados de maneira contrária a qualquer tratamento morfológico anterior (BREMER, 1994; KATINAS et al., 2008; KIM et al., 2002). A partir de estudos morfológicos em grados basais, Roque \& Funk (2013) reconheceram características exclusivas das anteras, cipsela e pápus entre Stifftioideae e Wunderlichioideae sem, contudo, distinguir sinapomorfias morfológicas para Stifftieae. Segundo, ainda, Panero e Funk (2008), a tribo Stifftieae está, atualmente, dividida em 3 clados: o ramo basal, composto apenas pelo gênero Stifftia e 2 clados irmãos, clado 
Gongylolepis (incluindo Glossarion Maguire \& Wurdack, Eurydochus Maguire \& Wurdack, Gongylolepis R.H. Schomb., Neblinaea Maguire \& Wurdack, Achnopogon Maguire, Steyerm. \& Wurdack, Duidaea S.F. Blake, Salcedoa Jiménez Rodr. \& Katinas e Quelchia N.E. Br.) e o clado Hyaloseris (incluindo Dinoseris Griseb. e Hyaloseris Griseb.).

Stifftieae, atualmente conta com 11 gêneros e cerca de 44 espécies, com distribuição sul americana (Argentina, Bolívia, Brasil, Colômbia, Guiana, Guiana Francesa e Venezuela).

\section{Descrição}

Arbustos, árvores ou lianas, raramente subarbustos, sem látex. Folhas simples, alternas, algumas vezes reunidas no ápice, ou alternas a opostas reunidas em braquiblastos, ou opostas; lâmina foliar com margem inteira a serrulada, revoluta ou parcialmente revoluta, tomentosa, lanosa, pubescente, glabrescente ou glabra, peciolada, algumas vezes pecíolo amplexicaule ou séssil a subséssil. Capitulescência monocéfala, corimbiforme, paniculiforme, racemiforme ou glomeruliforme, terminal, subterminal ou axilar; receptáculo epaleáceo, esparsamente hirsuto e foveolado em Neblinaea, glabro em Quelchia. Capítulos isomorfos, discoides, homógamos; invólucro cilíndrico, campanulado ou hemisférico, multisseriado, imbricado, desigual ou subigual. Flores 1-150, corola tubulosa, com 5 lobos enrolados no ápice ou profundamente divididos e enrolados em Stifftia, bilabiada ou ligulada, algumas vezes lobos enrolados no ápice, glabra ou pubérula, alva, creme, amarela, arroxeada, vermelha ou avermelhada; estames exsertos (Figuras $3 \mathrm{~F}$ e $4 \mathrm{~A}$ ), anteras alvas, creme, avermelhadas, roxas ou marrons, apêndice apical agudo ou acuminado, base geralmente caudada, caudas curtas ou longas, papilosas ou pubérulas, livres ou conadas com a base dos estames adjacentes; estilete alvo, creme, rosa, vermelho, roxo, bífido, bilobado ou clavado, ápice obtuso ou arredondado a agudo, glabro. Cipselas cilíndricas, prismáticas, obovadas, cilíndrico-turbinadas ou truncadas a atenuadas no ápice, geralmente 10-costadas, densamente pubescentes, vilosas, puberulentas, esparsamente pilosas no ápice, glabrescentes ou glabras (Figura 4B); pápus 3-4(5) séries, vistoso, vermelho, rosa, laranja, bronze, creme ou alvo; 
em geral, cerdoso, ou as internas subpaleáceas (Figura 4C), 100-150(-200) elementos, decíduas ou persistentes.

No Brasil, Stifftieae está representada por 5 gêneros: Gongylolepis, com 3 espécies distribuídas no Amazonas e Roraima (Figura 3F); Stifftia, com 5 espécies, todas endêmicas (Figuras 3G-H); Glossarion, Eurydochus e Neblinaea, com 1 espécie cada e todas restritas ao Amazonas. A maioria das espécies é encontrada exclusivamente em bordas de mata da floresta amazônica ou atlântica.

\section{Chave de identificação para os gêneros de Stifftieae no Brasil}

1. Corola actinomorfa, tubulosa (Figura 4A) Stifftia

1'. Corola zigomorfa, bilabiada ou ligulada 2

2. Lâmina foliar elíptica, tomentosa na face abaxial Glossarion

2'. Lâmina foliar obovada ou oblanceolada, glabra. 3

3. Invólucro cilíndrico, 0,5-0,8 cm larg.; capítulo com 2-5 flores... Neblinaea 3’. Invólucro campanulado, 1,8-5 cm larg.; capítulo com (9)13-50 flores .... 4

4. Folha peciolada (pecíolo 1-4 cm compr.); lâmina foliar com ápice acuminado; brácteas involucrais subiguais, pubescentes; cipsela pubescente, pápus mais curto que a corola. Eurydochus 4'. Folha geralmente séssil a subséssil; lâmina foliar com ápice arredondado, retuso ou obtuso; brácteas involucrais graduais, glabras (Figura 3F); cipsela glabra, pápus do mesmo tamanho ou maior que a corola Gongylolepis

\section{Literatura recomendada}

BREMER, K. Asteraceae: cladistics and classification. Portland: Timber Press, 1994.

CABRERA, A. L. Mutisieae: systematic review. In: HEYWOOD, V. H.; HARBORNE, J. B.; TURNER, B. L. (Ed.). The Biology and Chemistry of the Compositae. London: Academic Press, 1977. v. 2. p. 1039-1066. 
DON, D. Descriptions of new genera and species of the class Compositae belonging to the Floras of Peru, Mexico, and Chile. The Transactions of the Linnean Society of London, London, v. 16, n. 2, p. 169-303, 1830.

FUNK, V. A. et al. Classification of Compositae. FUNK, V. A. et al. (Ed.). Systematics, Evolution and Biogeography of Compositae. Vienna: IAPT, 2009. p. 171-188.

HIND, D. J. N. Tribe Mutisieae. In: KADEREIT, J.W.; JEFFREY, C. (Ed.). The Families and Genera of Vascular Plant: v. VIII: Flowering Plants Eudicots: Asterales. Berlin: Springer-Verlag, 2007. p. 90-123.

JEFFREY, C. Systema Compositarum (Asteracearum) nova. Botanicheskii Zhurnal, [S.1.], n. 89, p. 1817-1822, 2004.

KATINAS, L. et al. The subfamily Mutisioideae (Asteraceae). The Botanical Review, Bronx, n. 74, p. 469-716, 2008.

KIM, H. G. et al. Systematic implications of $\mathrm{ndhF}$ sequence variation in the Mutisieae (Asteraceae). Systematic Botany, [S.1.], n. 27, p. 598-609, 2002.

MAGUIRE, B. et al. The botany of the Guayana Highland. Memoirs of the New York Botanical Garden, New York, part. 2, n. 9, p. 235-392, 1957.

ORTIZ, S. The basal Grade of the Asteraceae: the fate of Mutisieae (sensu Cabrera) and the Carduoideae. FUNK, V. A. et al. (Ed.). Systematics, Evolution and Biogeography of Compositae. Vienna: IAPT, 2009. p. 193-213.

PANERO, J. L.; FUNK, V. A. The value of sampling anomalous taxa in phylogenetic studies: major clades of the Compositae revealed. Molecular Phylogenetics and Evolution, Orlando, v. 47, n. 2, p. 757-782, 2008.

PEREIRA, A. C. M. et al. Notas nomenclaturais em Stifftia J.C.Mikan (Stifftieae-Asteraceae). Acta Botânica Brasílica, Porto Alegre, v. 24, n. 3, p. 877-881, 2010.

PRUSKI, J. F. Asteraceae (Compositae). St. Louis: The Missouri Botanical Garden, 2004.

PRUSKI, J. F. Compositae of the Guayana Highland - V. The Mutisieae of the Lost World of Brazil, Colombia, and Guyana, Boletim do Museu Paraense de História Natural e Ethnographia, n. 7, p. 335-392, 1991. 
PRUSKI, J. F. Compositae of the Guayana Highland - II. Novelties in Gongylolepis and Stenopadus (Mutisieae). Annals of the Missouri Botanical Garden, Saint Louis, v. 76, n. 4, p. 993-1003, 1989a.

PRUSKI, J. F. Notes on the Compositae of the Guayana Highland - I. A new species of Stomatochaeta and the reduction of Guaicaia to Glossarion (Compositae: Mutiseae). Brittonia, Bronx, v. 41, n. 1, p. 35-40, 1989b.

ROBINSON, H. Two New Species of Stifftia with Notes on Relationships of the Genus (Asteraceae: Mutisieae). Systematic Botany, [S.1.], v. 16, n. 4, p. 685-692, 1991.

ROQUE, N.; FUNK, V. A. Morphological characters add support for some members of the basal grade of Asteraceae. Botanical Journal of the Linnean Society, London, v. 171, n. 3, p. 568-586, 2013. 